August 2012

\title{
Clinical review of pediatric pilocytic astrocytomas treated at a tertiary care hospital in Pakistan
}

Muhib A. Khan

Henry Ford Hospital, Detroit, Michigan, USA,

Saniya Siraj Godil

Aga Khan University

Halima Tabani

Aga Khan University

Sukaina A Panju

Aga Khan University

S. Ather Enam

Agha Khan University, ather.enam@aku.edu

Follow this and additional works at: http://ecommons.aku.edu/pakistan_fhs_mc_surg_surg

Part of the Nephrology Commons

\section{Recommended Citation}

Khan, M., Godil, S., Tabani, H., Panju, S., Enam, S. (2012). Clinical review of pediatric pilocytic astrocytomas treated at a tertiary care hospital in Pakistan.

Available at: http://ecommons.aku.edu/pakistan_fhs_mc_surg_surg/268 


\title{
Original Article
}

\section{Clinical review of pediatric pilocytic astrocytomas treated at a tertiary care hospital in Pakistan}

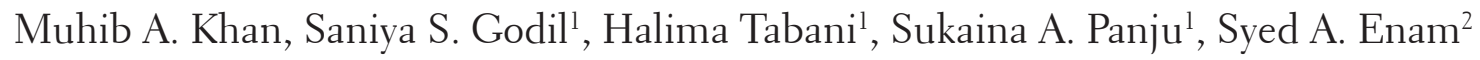 \\ Department of Neurology, Henry Ford Hospital, Detroit, Michigan, USA, 'Department of Neurosurgery, Aga Khan University Medical College, Karachi, \\ ${ }^{2}$ Department of Neurosurgery, Aga Khan University, Karachi, Pakistan \\ E-mail: *Muhib A. Khan - muhibalamkhan@hotmail.com; Saniya S. Godil - saniyasiraj@hotmail.com; Halima Tabani - halima_tabani@hotmail.com; \\ Sukaina A. Panju - sukaina.panju@gmail.com; Syed A. Enam - ather.enam@aku.edu \\ *Corresponding author
}

Copyright: $\odot 2012$ Khan MA. This is an open-access article distributed under the terms of the Creative Commons Attribution License, which permits unrestricted use, distribution, and reproduction in any medium, provided the original author and source are credited.

\begin{abstract}
Background: Pilocytic Astrocytoma (PA) is a common type of brain tumor in the pediatric population. They have a fairly good prognosis. This study describes PAs in detail, with a focus on the demographic factors, presenting features, management and prognosis, and aims, to identify the negative outcome predictors in our population, which can affect the course of the disease. This article will add to the understanding of PAs from a third world perspective.
\end{abstract}

Methods: The Aga Khan University medical records (1995-2007) were reviewed, to study the clinical features, management, and outcome of patients $(0-15$ years) with Pilocytic Astrocytomas (PAs) in our population. After a thorough review of the medical records, all the PAs diagnosed on the basis of histopathology at our Pathology Laboratory, during this period, were included in the study.

Results: Twenty-two patients were included with a mean age of 9.25 years. Male-to-female ratio was $1: 1$. The most common presenting feature was a sign of increased intracranial pressure. The most common location was the cerebellum followed by the cerebrum. Fifteen patients underwent maximum surgical resection. Three had recurrence, despite no residual tumor. There were 10 Intensive Care Unit (ICU) admissions and one inpatient mortality. Fifteen patients followed up in the clinic: Eight had recurrence and four underwent repeat surgery (three showed clinical improvement). Hydrocephalus was a predictor of ICU admission. Solid consistency was found to be a marker of recurrence.

Conclusion: Pilocytic Astrocytomas are the most common pediatric brain tumors in our population, commonly located in the cerebellum. Complete resection is the best treatment option, but some tumors are aggressive and recurrence is not uncommon. The possible negative outcome predictors are age, source of admission, extent of resection, hydrocephalus, and solid consistency.

Key Words: Pediatric brain tumors, pilocytic astrocytomas, prognostic factors

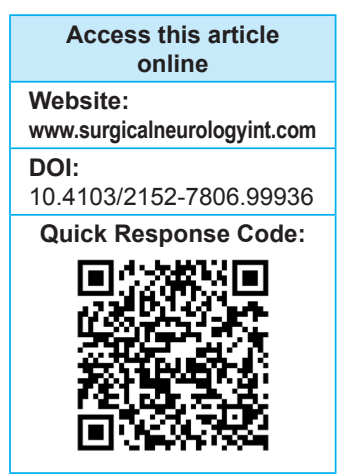




\section{INTRODUCTION}

Pilocytic Astrocytoma (PA) is a common type of brain tumor in the pediatric population. PAs comprise of $19.1 \%$ of all pediatric brain tumors in the age group $0-14$ years, ${ }^{[1]}$ and have been reported to be the most common gliomas and cerebellar tumors in children. ${ }^{[6,8]}$ They can involve the entire neuroaxis, but the cerebellum is the most common site of origin. Due to lack of populationbased studies, the actual incidence is not clear, but Burkhard et al. ${ }^{[7]}$ reported an incidence of 4.8 per one million in the Canton of Zurich, Switzerland, while the Central Brain Tumor Registry of the United States (CBTRUS) reports it to be 2.9 per million in the US. ${ }^{[1]}$ PAs are associated with a relatively benign clinical course. They have a fairly good prognosis with a five-year survival rate of $80-90 \%{ }^{[12]}$ and a 10 -year survival rate of $81 \%{ }^{[13]}$ depending on the tumor location and extent of resection. This may reflect the tumor's slow growth and discrete nature, which allow complete surgical resection. ${ }^{[1]}$ However, some of these tumors are more aggressive, have a higher rate of recurrence, and a poor prognosis. It is important to identify these patients correctly, as surgical treatment is usually curative. ${ }^{[3]}$ In this article, we present our experience with PAs in the pediatric population. This study describes PAs in detail, with a focus on the demographic factors, presenting features, management and prognosis, and aims, to identify the negative outcome predictors in our population, which can affect the course of the disease. This article will add to the understanding of PAs from a third world perspective.

\section{MATERIALS AND METHODS}

This was a retrospective cross-sectional study. The Aga Khan University Hospital (AKUH) medical records were reviewed for a twelve-year period (1995 - 2007), after approval from the Ethical Review Committee of the AKUH, to identify pediatric brain tumor patients. The pediatric population was defined as patients aged below 15 years at the time of admission in our hospital. The patients were referred to our institution by various physicians in the community. As AKUH is one of the few centers in Pakistan operating on pediatric brain tumors, our referral catchment area was countrywide. After a thorough review of the medical records, all PAs diagnosed on the basis of histopathology at our Pathology Laboratory, during this period, were included in the study. Data was collected using a proforma on the following variables: age, gender, source of admission (Emergency Room or Consulting Clinic), presenting symptoms, radiological findings, tumor location, surgical management, adjuvant therapy (radiotherapy and chemotherapy), ICU admission, Inpatient mortality, neurological condition on discharge, duration of follow-up, neurological condition on follow-up in the clinic, recurrence, repeat surgery for recurrence, and late mortality. The association between the patient characteristics of age, gender, source of admission, hydrocephalus, and consistency, with the outcomes of ICU admission, recurrence, and repeat surgery were tested using Fisher's exact tests. On account of the small sample sizes, multivariate modeling was not possible. $P$-values less than 0.05 were considered significant. All analyses were done using the SAS version 9.2 .

\section{RESULTS}

During the 12-year period of 1995 - 2007, 102 pediatric brain tumors were operated and $22(21.6 \%)$ patients were diagnosed with Pilocytic Astrocytoma, based on the histopathology.

\section{Demographics}

The mean age of the patients was 9.25 years, with most of the patients presenting in the adolescent age group of 10 to 15 years [Figure la]. Gender distribution was equal, with a male-to-female ratio of $1: 1$, but there was a male preponderance in the higher age group [Figure lc]. Out of 22 patients, $18(81.8 \%)$ were admitted from consulting clinics, while four $(18.2 \%)$ were admitted through the Emergency Room. The duration of stay in the hospital ranged from two days to 46 days, with an average stay in the hospital of 12.4 days. The duration of stay in the hospital was longer in the younger age group [Figure ld].

\section{Presenting clinical and radiological features}

Most of the patients (81.8\%) presented with a Glasgow Coma Scale (GCS) of $15 / 15$. Only one patient had a GCS of 3 and one had a GCS of 7. All the patients presented with more than one clinical sign, with signs of increased intracranial pressure $(86.4 \%)$ being the most common, followed by focal neurological signs (52.9\%) [Table 1].

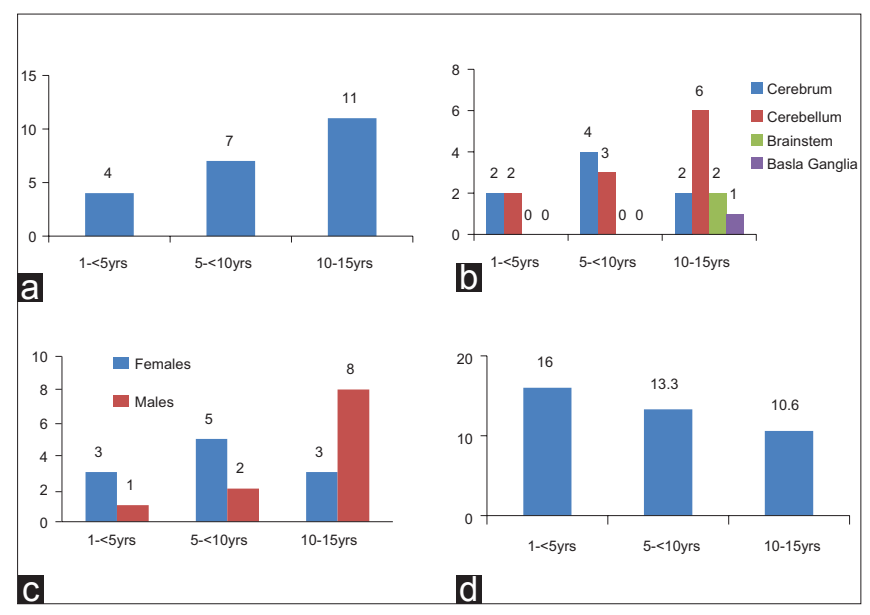

Figure I:Variation of (a) Distribution, (b) Location, (c) Gender, and (d) Duration of stay, with age 
A majority of our patients were diagnosed radiologically on the basis of magnetic resonance imaging (MRI). The MRI was used as a single diagnostic modality in $12(54.5 \%)$ patients, while computed tomography (CT) was used in three (13.6\%) patients, but seven (31.8\%) patients underwent both CT and MRI. Hydrocephalus was seen in nine $(40.9 \%)$ cases. A cystic component was present in nine $(40.9 \%)$ cases, while the remaining 13 (59.1\%) were of solid consistency. A total of six (27.3\%) cases showed contrast enhancement.

\section{Location of tumors}

Pilocytic Astrocytomas showed a predilection for the cerebellum; 11 (50\%) were found in the cerebellum, eight (36.4\%) in the cerebrum, two $(9.1 \%)$ in brainstem, and one $(4.5 \%)$ in the basal ganglia [Figure 2]. The location of the tumor also varied with age; the cerebrum was the most common location in the $5-10$ year age group, while the cerebellum was the most common location in the $10-15$ year age group [Figure lb]. Among all pediatric brain tumors $(n=102)$, PAs were found to be the most common cerebral tumors $(19.5 \%)$ and the second most common cerebellar tumors (33.3\%), the most common being medulloblastoma (36.4\%).

\section{Histological features}

Table 2 shows the histopathological details of all the tumors. Rosenthal fibers were present in 15 (68.2\%) cases and microcysts were identified in 12 (54.5\%), which were also associated with eosinophilic bodies. Fibrillary background was found in $17(77.3 \%)$ of the tumors, but five $(22.7 \%)$ were found to have a myxoid background. Other features were apparent only in a few cases: necrosis in three $(13.6 \%)$, vascularity in five $(22.7 \%)$, and mitoses in three $(13.6 \%)$ of the cases.

\section{Management}

Surgical resection remained the mainstay of treatment, as all our patients underwent craniotomy, mostly for resection, with only two undergoing a biopsy. Out of these two patients, one died during the hospital stay and the other one did not show any clinical improvement (CI) on discharge.

Complete resection was attempted in 15 (68.2\%) patients. Postoperative imaging was done in 10 of these patients; there was no residual tumor seen in seven of them, but three of the patients had a residual tumor. Even after no evidence of residual tumor in postoperative imaging, three patients had recurrence; one was given radiotherapy after repeat surgery, while one was treated with chemotherapy without any repeat surgery. The former showed clinical improvement, but the latter did not. Of the five (22.7\%) patients who underwent partial resection, one was treated with postoperative radiotherapy, and one had late mortality, after 8.4 years, during the initial postoperative course of repeat craniotomy, due to recurrence of tumor. An extraventricular drain (EVD) was placed in seven
Table 1: Presenting complaints of the patients

\begin{tabular}{lc}
\hline Presenting symptoms & $\boldsymbol{n =} \mathbf{2 2}$ \\
\hline Focal Neurological Signs & \\
Motor Deficit in Limbs & 7 \\
Cranial Nerve Deficit & 4 \\
Seizures & 5 \\
Balance Difficulty & 5 \\
Symptoms of Raised ICP & 19 \\
Headache & 17 \\
Nausea & 3 \\
Vomiting & 14 \\
Drowsiness & 3 \\
\hline
\end{tabular}

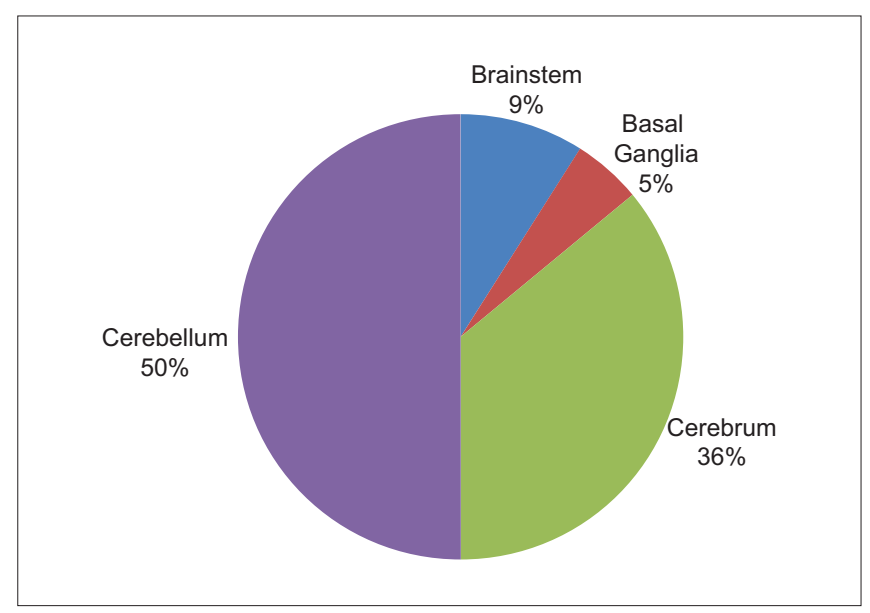

Figure 2: Location of pilocytic astrocytomas

Table 2: Different histological features of pilocytic astrocytomas

\begin{tabular}{lc}
\hline Histological features & $\%$ \\
\hline Fibrillary Background & 77.8 \\
Rosenthal Fibers & 66.7 \\
Microcysts & 55.6 \\
Eosinophilic Bodies & 55.6 \\
Cellular Pleomorphism & 27.8 \\
Vascularity & 22.2 \\
Myxoid Background & 22.2 \\
Calcification & 11.1 \\
Necrosis & 11.1 \\
Mitoses & 11.1 \\
\hline
\end{tabular}

patients before craniotomy, with two of them needing a ventriculoperitoneal shunt (VPS) later on. VPS alone was placed in three patients. Figure 3 shows how the extent of resection of the tumor affected the subsequent management and outcome of the patients.

\section{Outcome}

Ten (45\%) patients were admitted in the Intensive 


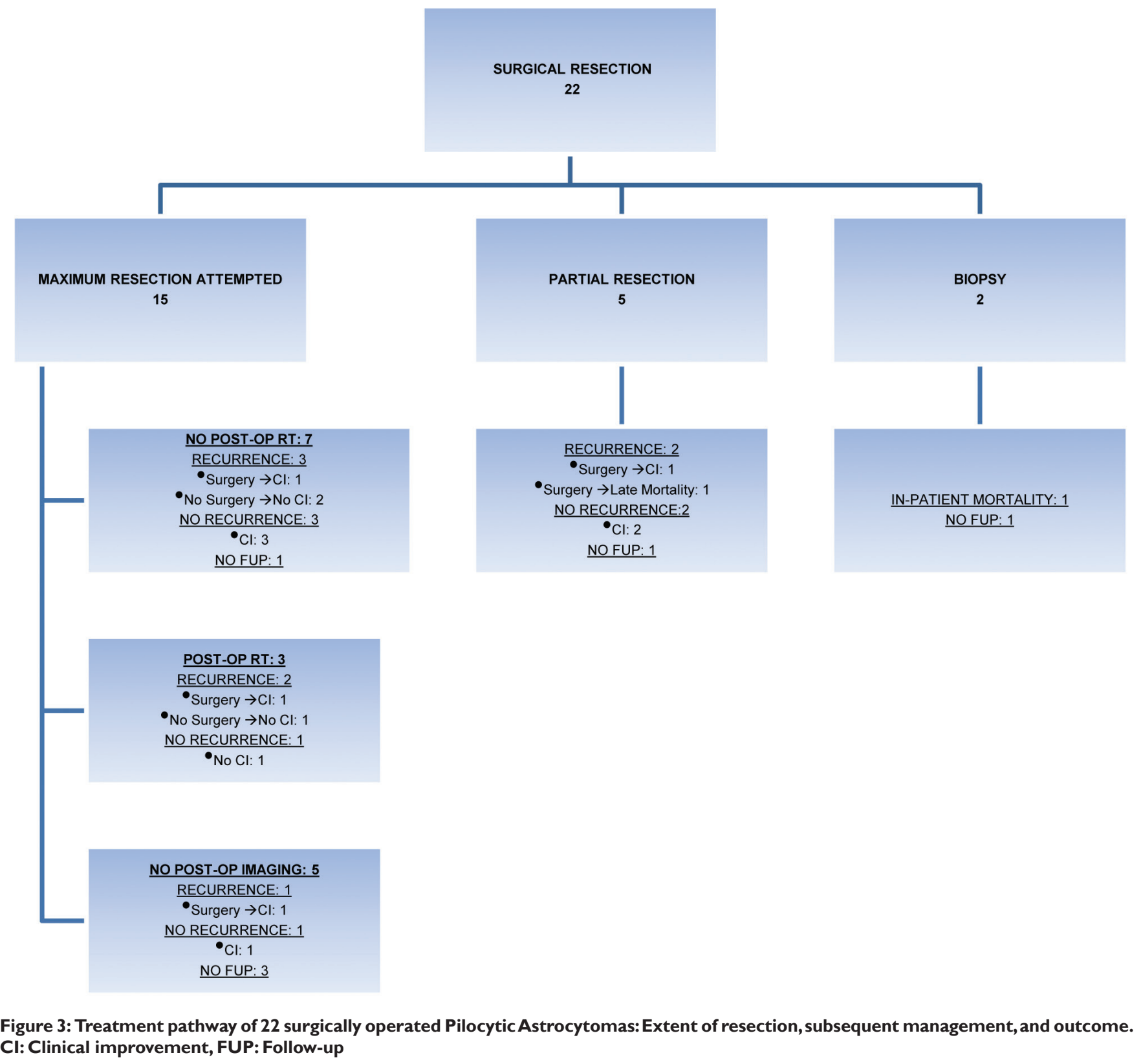

Care Unit (ICU) and one (4.5\%) patient died during the hospital course. This patient underwent biopsy of a tumor in the cerebrum. Most of the patients, 20 (90.9\%), had neurological improvement on discharge. Out of 22, $15(68.2 \%)$ patients came for follow-up visits in the clinic and 11 (73.3\%) showed progressive neurological improvement. The follow-up time period ranged from three months to 12 years, with a mean follow-up period of 3.72 years [Figure 4]. Recurrence was observed in eight $(53.3 \%)$ of these patients, of whom four underwent repeat surgery. The time of recurrence ranged from eight months to 8.4 years and the mean time period for recurrence was found to be 3.7 years. Patients who did not have repeat surgery showed no clinical improvement, while three of the four patients who underwent repeat surgery showed clinical improvement, and one patient died after repeat surgery due to status epilepticus.

\section{Predictors of negative outcome}

A number of factors (e.g., age, source of admission, gender, location of tumor, cystic component, contrast enhancement, hydrocephalus, and extent of resection) were considered, which could affect the postoperative course, functional status, and prognosis of the patients [Table 3]. Inpatient mortality and late mortality, were both seen in the age group of $1-<5$ years, although recurrence was more common in the older age groups. Out of the 10 ICU admissions, three (33\%) were females $(P=$ 017). Tumor recurrence was higher in males $(P=0.019)$. Admission through the Emergency Room (ER) led to 


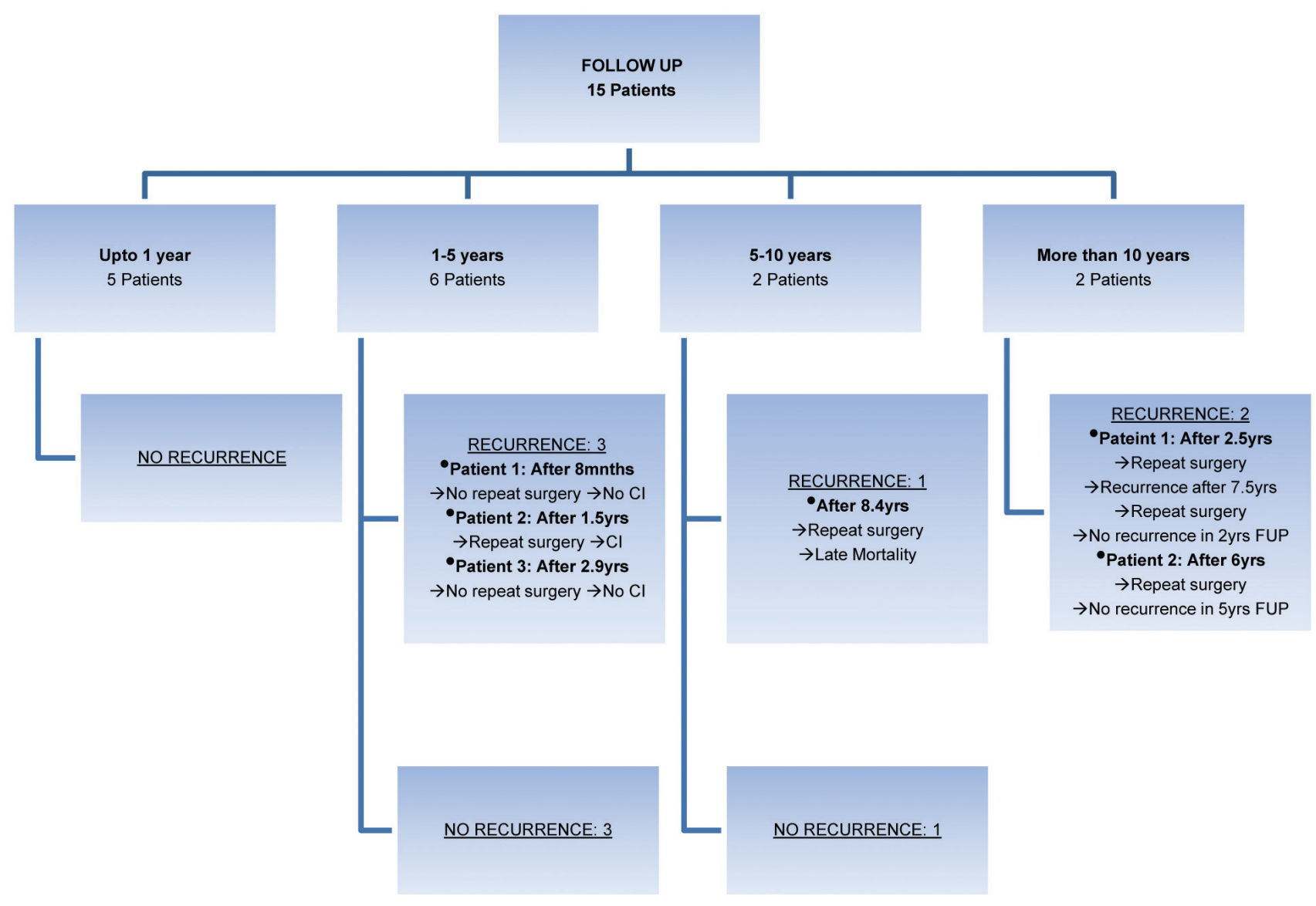

Figure 4: Follow-up of I 5 patients ranging from 0 - 12 years. Cl: Clinical improvement, FUP: Follow-up

Table 3: Predictors of negative outcome (age, source of admission, solid consistency, and hydrocephalus) in patients with ICU admission, Inpatient mortality, recurrence, and late mortality

\begin{tabular}{|c|c|c|c|c|c|c|c|c|c|c|c|}
\hline & \multicolumn{3}{|c|}{ Age } & \multicolumn{2}{|c|}{ Gender } & \multicolumn{2}{|c|}{$\begin{array}{l}\text { Source of } \\
\text { Admission }\end{array}$} & \multicolumn{2}{|c|}{ Hydrocephalus } & \multicolumn{2}{|c|}{ Consistency } \\
\hline & $1-<5$ & $5-<10$ & $10-15$ & Male & Female & ER & CC & Yes & No & Solid & Cystic \\
\hline ICU Admission & $\begin{array}{c}1 \\
25 \%\end{array}$ & $\begin{array}{c}1 \\
25 \%\end{array}$ & $\begin{array}{c}2 \\
50 \%\end{array}$ & $\begin{array}{c}1 \\
25 \%\end{array}$ & $\begin{array}{c}3 \\
75 \%\end{array}$ & $\begin{array}{c}3 \\
75 \%\end{array}$ & $\begin{array}{c}1 \\
25 \%\end{array}$ & $\begin{array}{c}1 \\
25 \%\end{array}$ & $\begin{array}{c}3 \\
75 \%\end{array}$ & $\begin{array}{c}1 \\
25 \%\end{array}$ & $\begin{array}{c}3 \\
75 \%\end{array}$ \\
\hline Inpatient Mortality & $\begin{array}{c}1 \\
100 \%\end{array}$ & $\begin{array}{c}0 \\
0 \%\end{array}$ & $\begin{array}{c}0 \\
0 \%\end{array}$ & $\begin{array}{c}0 \\
0 \%\end{array}$ & $\begin{array}{c}1 \\
100 \%\end{array}$ & $\begin{array}{c}1 \\
100 \%\end{array}$ & $\begin{array}{c}0 \\
0 \%\end{array}$ & $\begin{array}{c}0 \\
0 \%\end{array}$ & $\begin{array}{c}1 \\
100 \%\end{array}$ & $\begin{array}{c}0 \\
0 \%\end{array}$ & $\begin{array}{c}1 \\
100 \%\end{array}$ \\
\hline Recurrence & $\begin{array}{c}1 \\
12.5 \%\end{array}$ & $\begin{array}{c}4 \\
50 \%\end{array}$ & $\begin{array}{c}3 \\
37.5 \%\end{array}$ & $\begin{array}{c}4 \\
50 \%\end{array}$ & $\begin{array}{c}4 \\
50 \%\end{array}$ & $\begin{array}{c}1 \\
12.5 \%\end{array}$ & $\begin{array}{c}7 \\
87.5 \%\end{array}$ & $\begin{array}{c}5 \\
62.5 \%\end{array}$ & $\begin{array}{c}3 \\
37.5 \%\end{array}$ & $\begin{array}{c}3 \\
37.5 \%\end{array}$ & $\begin{array}{c}5 \\
62.5 \%\end{array}$ \\
\hline Repeat Surgery & $\begin{array}{c}1 \\
20 \%\end{array}$ & $\begin{array}{c}3 \\
60 \%\end{array}$ & $\begin{array}{c}1 \\
20 \%\end{array}$ & $\begin{array}{c}2 \\
40 \%\end{array}$ & $\begin{array}{c}3 \\
60 \%\end{array}$ & $\begin{array}{c}0 \\
0 \%\end{array}$ & $\begin{array}{c}5 \\
100 \%\end{array}$ & $\begin{array}{c}4 \\
80 \%\end{array}$ & $\begin{array}{c}1 \\
20 \%\end{array}$ & $\begin{array}{c}2 \\
40 \%\end{array}$ & $\begin{array}{c}3 \\
60 \%\end{array}$ \\
\hline Late Mortality & $\begin{array}{c}1 \\
100 \%\end{array}$ & $\begin{array}{c}0 \\
0 \%\end{array}$ & $\begin{array}{c}0 \\
0 \%\end{array}$ & $\begin{array}{c}1 \\
100 \%\end{array}$ & $\begin{array}{c}0 \\
0 \%\end{array}$ & $\begin{array}{c}0 \\
0 \%\end{array}$ & $\begin{array}{c}1 \\
0 \%\end{array}$ & $\begin{array}{c}1 \\
100 \%\end{array}$ & $\begin{array}{c}0 \\
0 \%\end{array}$ & $\begin{array}{c}1 \\
100 \%\end{array}$ & $\begin{array}{c}0 \\
0 \%\end{array}$ \\
\hline
\end{tabular}

three (30\%) ICU admissions, but did not affect the longterm clinical outcome. Hydrocephalus was found to be a negative outcome predictor in terms of ICU admission, repeat surgery, and late mortality [Tables 3 and 4]. The extent of resection was also a negative outcome predictor in terms of Inpatient mortality and late mortality [Figure 3]. The solid consistency of tumors led to a poor prognosis, as it was associated with a greater number of ICU admissions, recurrence of tumors, and repeat surgeries $(60 \%)$ [Tables 3 and 4 ]. 
Table 4: Associations of demographic and clinical characteristics with outcomes of interest

\begin{tabular}{|c|c|c|c|c|c|c|c|c|}
\hline Variable & Response & $\mathbf{N}$ & $\begin{array}{c}\text { \# with ICU } \\
\text { admission } \\
(\%)\end{array}$ & P-value & $\begin{array}{c}\text { \# with } \\
\text { Recurrence } \\
(\%)\end{array}$ & $\boldsymbol{P}$-value & $\begin{array}{c}\text { \# with Repeat } \\
\text { surgery } \\
(\%)\end{array}$ & $P$-value \\
\hline Overall & & 19 & $10(53)$ & & $8(42)$ & & $4(21)$ & \\
\hline \multirow[t]{3}{*}{ Age } & $<5$ & 5 & $3(60)$ & $>0.99$ & $1(20)$ & 0.435 & $1(20)$ & 0.309 \\
\hline & $5-<10$ & 6 & $3(50)$ & & $2(33)$ & & $0(0)$ & \\
\hline & $10-15$ & 8 & $4(50)$ & & $5(63)$ & & $3(38)$ & \\
\hline \multirow[t]{2}{*}{ Gender } & Male & 10 & $7(70)$ & 0.178 & $7(70)$ & 0.019 & $4(40)$ & 0.086 \\
\hline & Female & 9 & $3(33)$ & & $1(11)$ & & $0(0)$ & \\
\hline \multirow[t]{2}{*}{ Source of Admission } & ER & 5 & $3(60)$ & $>0.99$ & $4(80)$ & 0.110 & $2(40)$ & 0.272 \\
\hline & Clinic & 14 & $7(50)$ & & $4(29)$ & & $2(14)$ & \\
\hline \multirow[t]{2}{*}{ Hydrocephalus } & Yes & 11 & $10(91)$ & $<0.001$ & $7(64)$ & 0.058 & $4(36)$ & 0.103 \\
\hline & No & 8 & $0(0)$ & & $1(13)$ & & $0(0)$ & \\
\hline \multirow[t]{2}{*}{ Consistency } & Solid & 6 & $4(67)$ & 0.628 & $6(100)$ & 0.001 & $2(33)$ & 0.557 \\
\hline & Cystic & 13 & $6(46)$ & & $2(15)$ & & $2(15)$ & \\
\hline
\end{tabular}

\section{DISCUSSION}

Pilocytic Astrocytomas were found to be the most common pediatric brain tumors $(21.6 \%)$ in our study population, which was comparable to the CBTRUS, ${ }^{[1]}$ which showed that the incidence of PAs was $19.1 \%$ in the $0-14$ years age group, and Rickert and Paulus, ${ }^{[19]}$ who observed that PAs comprised of $23.5 \%$ of their study population. However, some studies showed that prevalence could be as low as $5.5 \%,{ }^{[7]}$ although there was no evidence of increased incidence of PA in any racial or ethnic group. ${ }^{[18]}$ The male-to-female ratio in our population was $1: 1$, which was comparable to 1.12 according to Burkhard et al. ${ }^{[7]}$ and the general trend of no gender predilection observed in PAs. ${ }^{[6]}$ The mean age of 9.25 years observed in our study was similar to the mean age of 8 years noted by Krieger et al. ${ }^{[15]}$ and 10.6 years observed in a study by Malik et al. ${ }^{[16]}$ Although PA was a slow growing tumor, four (18.4\%) of the patients were admitted through ER. This was unusual and it had a significant impact on the prognosis of the patient. The most common presenting complaints were signs of increased intracranial pressure (ICP) (86.4\%) and focal neurological deficits (50\%), which were comparable to other studies. ${ }^{[2,3,9]}$

Pilocytic Astrocytomas could arise in various locations in the neuroaxis, such as, the optic nerve, optic chiasm, hypothalamus, cerebellum, brain stem, thalamus, basal ganglia, and cerebral hemispheres. In our study, they showed a predilection toward the posterior fossa, particularly the cerebellum (50\%). Aarsen et al. ${ }^{[2]}$ and Fernandez et al. ${ }^{[9]}$ reported a similar trend, but their cases were also located in the optic chiasm and spinal cord. The MRI and CT scan showed a cystic component in $40.9 \%$ of the patients and contrast enhancement in 20.3\%. PAs appearing solid on the MRI were presumed to be more aggressive. Our study also showed differences in the outcome of solid and cystic PAs, but these were not statistically significant. Strong et al. ${ }^{[21]}$ evaluated the radiological images of PAs with regard to tumor distribution, size, morphological appearance, calcification, and degree of contrast enhancement, in their study, but we were unable to distinguish tumors that would follow an aggressive course from the tumors that would behave in a more benign manner. Thus, they concluded that imaging features were unreliable in predicting clinical behavior. Maximum resection was attempted in 15 patients; seven $(46.7 \%)$ of them had no residual tumor, five $(33.3 \%)$ had residual tumor, and three $(20 \%)$ did not have any postoperative imaging. Studies showed that direct neurosurgical evaluation of the extent of resection was surprisingly unreliable, and postoperative, contrast-enhanced, cross-sectional imaging, preferably MRI, was essential for definitive assessment. ${ }^{[1+20,22]}$ Complete resection led to a better outcome, with most of the patients showing clinical improvement, and there was no Inpatient or late mortality. This showed the curative potential of resection, with no identifiable tumor left behind, as shown by other studies. ${ }^{[7,9]}$ However, three $(42.9 \%)$ of the seven patients in our study showed recurrence, even though there was no evidence of a postoperative residual tumor on imaging. This could be correlated with the findings of Strong et al., ${ }^{[21]}$ which stated more than one-third of their patients with PAs followed an unusually aggressive course, with progression, 
or a recurrent tumor identified despite concurrent treatment.

There exists a subset of patients who have an aggressive clinical course and require multiple resections or other therapies to control tumor growth. ${ }^{[22]}$ The reason for the aggressive behavior of the PAs, compared with most other studies describing PA as a benign entity, is unclear. Patients with only a tumor biopsy done, did not show any clinical improvement and one had Inpatient mortality. Partial resection led to recurrence in two (40\%) patients and late mortality in one $(20 \%)$ patient. Adjuvant therapy in the form of chemo- and radiotherapy was not necessary in PAs that were completely resected. ${ }^{[9]}$ Very few patients with recurrence or partially resected tumors underwent chemotherapy and radiotherapy in our study and did not show clinical improvement if not combined with repeat resection.. Impact on survival by these adjuvant modalities is still controversial ${ }^{[7]}$ and careful patient selection must be done.

Out of the total, 15 patients came for follow-up in clinics. Only one late mortality was seen after 8.4 years, although eight patients had recurrence, and four underwent repeat surgery. Those patients who underwent repeat surgery showed clinical improvement, while others did not. It was found in a study conducted, in 2001, that repeat surgery for tumors located in the cerebral hemispheres or cerebellum resulted in gross total resection or near total resection in all cases and resulted in long periods of progression-free survival, without further adjuvant treatment. ${ }^{[5]}$ The time of recurrence ranged from eight months to 8.4 years and the mean time period for recurrence was found to be 3.7 years, which was comparable to another study, which showed that recurrence occurs between one and eight years. ${ }^{[3]}$

Due to variations in the prognosis of all the patients, we tried to find out the predictors of negative outcomes. Previous studies have identified several risk factors for tumor recurrence / progression including, age, site, and extent of resection, although several of these remain controversial. ${ }^{[4,10,17]}$

Aarsen et al. ${ }^{[2]}$ found that disabilities were more significant in the supratentorial as compared to the infratentorial PAs. Berger et al..$^{[4]}$ noted that the extent of resection was significantly related to the recurrence of tumor. A retrospective study of 80 cases of PAs concluded that some clinicopathological factors, such as, partial resection, optochiasmatic location, invasion of the surrounding structures, and the pilomyxoid variant, had a worse prognosis. ${ }^{[9]}$ In our study population, age, gender, source of admission, hydrocephalus, solid consistency, and the extent of resection, were found to be poor prognostic factors, whereas, location of the tumor and contrast enhancement on imaging did not have any effect on the prognosis. Although these factors were suggestive of poor outcome, the statistical significance could not be determined, due to the small sample size. Therefore, further population-based studies should be conducted to validate the identified predictors of negative outcomes.

\section{CONCLUSION}

Pilocytic Astrocytomas are the most common pediatric brain tumors in our population and are most commonly located in the cerebellum. Complete surgical resection is the best treatment option for PAs. However, some tumors follow an aggressive course and recurrence is not uncommon. A second surgical resection after recurrence has a likelihood of better prognosis. The negative outcome predictors, according to our study, are age, source of admission, extent of resection, solid consistency, and hydrocephalus. As the number of cases in our study is small, there is a need to do a larger study, with more cases of PAs in the Pakistani population, to determine if there are any ethnic differences in the epidemiology, prognostic factors, and outcomes, as compared to other studies from different parts of the world.

\section{REFERENCES}

I. Available from: http://www.cbtrus.org/reports/reports.html [Last accessed on 2012 Mar 23].

2. Aarsen FK, Paquier PF, Reddingius RE, Streng IC,Arts WF, Evera-Preesman M, et al. Functional outcome after low-grade astrocytoma treatment in childhood. Cancer 2006; 106:396-402.

3. Abdollahzadeh M, Hoffman HJ, Blazer SI, Becker LE, Humphreys RP, Drake JM, et al.Benign cerebellar astrocytoma in childhood:Experience at the Hospital for Sick Children 1980-1992. Childs Nerv Syst 1994; 10:380-3.

4. Berger MS, Deliganis AV, Dobbins J, Keles GE.The effect of extent of resection on recurrence in patients with low grade cerebral hemisphere gliomas. Cancer 1994;74:1784-91.

5. Bowers DC, Krause TP, Aronson LJ, Barzi A, Burger PC, Carson BS, et al. Second surgery for recurrent pilocytic astrocytoma in children. Pediatr Neurosurg 200I;34:229-34.

6. Burger PC, Scheithauer BW, Paulus W, Szymas J, Giannini C, Kleihues P. Pathology and genetics of tumours of the nervous system. Lyon: IARC; 2000. p. 45-5I.

7. Burkhard C, Di Patre PL, Schuler D, Schüler G, Yașargil MG, Yonekawa Y, et al.A population-based study of the incidence and survival rates in patients with pilocytic astrocytoma. J Neurosurg 2003;98: I I70-4.

8. Farwell JR, Dohrmann GJ, Flannery JT. Central nervous system tumors in children. Cancer 1977;40:3 I23-32.

9. Fernandez C, Figarella-Branger D, Girard N, Bouvier-Labit C, Gouvernet J, Paz Paredes A, et al. Pilocytic astrocytomas in children: Prognostic factors--a retrospective study of 80 cases. Neurosurgery 2003;53:544-53; discussion 554-45.

10. Gajjar A, Sanford RA, Heideman R, Jenkins JJ,Walter A, Li Y, et al. Low-grade astrocytoma:A decade of experience at St.Jude Children's Research Hospital. J Clin Oncol 1997; 15:2792-9.

II. Garcia DM, Fulling KH. Juvenile pilocytic astrocytoma of the cerebrum in adults. A distinctive neoplasm with favorable prognosis. J Neurosurg 1985;63:382-6.

12. Gupta N, Banerjee A, Haas-Kogan D. Pediatric CNS tumors. Heidelberg: Springer-Verlag; 2004.

13. Hayostek CJ, Shaw EG, Scheithauer B, O'Fallon JR, Weiland TL, Schomberg PJ, et al.Astrocytomas of the cerebellum.A comparative clinicopathologic study of pilocytic and diffuse astrocytomas. Cancer 1993;72:856-69.

14. Kondziolka D, Lunsford LD, Martinez AJ. Unreliability of contemporary 
neurodiagnostic imaging in evaluating suspected adult supratentorial (lowgrade) astrocytoma. J Neurosurg 1993;79:533-6.

15. Krieger MD, Gonzalez-Gomez I, Levy ML, McComb JG. Recurrence patterns and anaplastic change in a long-term study of pilocytic astrocytomas. Pediatr Neurosurg 1997;27: I-I I.

16. MalikA, Deb P, Sharma MC, Sarkar C. Neuropathological spectrum of pilocytic astrocytoma:An Indian series of I 20 cases. Pathol Oncol Res 2006; I 2: I64-7I.

17. North CA, North RB, Epstein JA, Piantadosi S, Wharam MD. Low-grade cerebral astrocytomas. Survival and quality of life after radiation therapy. Cancer 1990;66:6-14.

18. Ohgaki H,Kleihues P.Epidemiology and etiology of gliomas.Acta Neuropathol 2005;109:93-108.
19. Rickert $\mathrm{CH}$, Paulus W. Epidemiology of central nervous system tumors in childhood and adolescence based on the new WHO classification. Childs Nerv Syst 200I; I7:503-II.

20. Sioutos PJ, Hamilton AJ, Narotam PK,Weinand ME. Unusual early recurrence of a cerebellar pilocytic astrocytoma following complete surgical resection. Case report and review of the literature.J Neurooncol 1996;30:47-54.

21. Strong JA, Hatten HP Jr, Brown MT, Debatin JF, Friedman HS, Oakes WJ, et al. Pilocytic astrocytoma: Correlation between the initial imaging features and clinical aggressiveness. AJR Am J Roentgenol 1993;161:369-72.

22. Wallner KE, Gonzales MF, Edwards MS, Wara WM, Sheline GE. Treatment results of juvenile pilocytic astrocytoma.J Neurosurg 1988;69:I7I-6. 